\title{
Tres preguntas sobre guerra y genocidio
}

\section{Q Walter Delrio}

Fecha de recepción: 15 de marzo de 2019. Fecha de aceptación: 15 de julio de 2019

Palabras clave

genocidio guerra pueblos originarios Patagonia

\section{Resumen}

A lo largo del siglo XX el aparato conceptual para abordar la violencia asociada a los procesos de formación estatal, colonialismo, segregación y exterminio étnico, guerras interestatales y de liberación, ha producido un importante corpus teórico en el que destacan las redefiniciones del concepto de guerra y la génesis de otros como genocidio. Este artículo aborda especialmente los usos de estos conceptos en el estudio de los procesos de sometimiento e incorporación de los pueblos originarios en el cono sur americano. Se abordan tres preguntas en relación con la definición de actores sociales, estado, agencia y pertinencia de dichos conceptos para el caso de Pampa y Norpatagonia.

\section{Three questions about war and genocide}

\begin{abstract}
Key words genocide war indigenous peoples Patagonia
\end{abstract}

\footnotetext{
* Instituto Patagónico de Estudios en Humanidades y Ciencias Sociales (IPEHCS), Consejo Nacional de Investigaciones Científicas y Técnicas (CONICET)/ Universidad Nacional del Comahue (UNCo) como Profesor de la Universidad Nacional de Río Negro (UNRN). San Carlos de Bariloche, Río Negro, Argentina. E-mail: wmdelrio@gmail.com
} 


\section{Introducción}

En los últimos años se ha producido una importante bibliografía sobre los procesos de sometimiento e incorporación estatal de los territorios y pueblos originarios de Pampa y Patagonia hacia fines del siglo XIX. Desde enfoques provenientes de distintas disciplinas y con diferentes agendas de investigación se han ampliado los márgenes en la construcción de los objetos de estudio. Esto, fundamentalmente, representó un cuestionamiento masivo a las narraciones historiográficas hegemónicas que por más de un siglo habían delimitado el campo en términos de una guerra ganada por la "civilización" sobre el "desierto" o, en otras palabras, aquello que quedaba definido como un "otro", la "barbarie" o los "salvajes". No obstante este proceso, en la sociedad argentina dichos estereotipos y perspectivas estigmatizadoras de la población originaria -especialmente del pueblo mapuche-tehuelche- continúan presentes y muy sólidos como puede advertirse en los conflictos sociales, debates en los medios de comunicación, sistemas educativo y de salud.

En efecto, desde el contexto de las campañas de sometimiento de la década de 1880 el discurso del sector político que capitalizó las mismas devino en discurso científico. Participó, así, de la elaboración cultural de la llamada "conquista del desierto" como un evento más de la historia universal, más aún de la historia natural, despolitizándolo y contribuyendo a la consolidación de estereotipos hegemónicos de lo indígena y de la misión civilizadora del estado.

Durante la última dictadura cívico-militar (1976-1983) se profundizó el discurso militarista sobre dichas campañas con la celebración de su centenario. En pleno conflicto limítrofe con la República de Chile, y durante la vigencia de un estado terrorista que extendía la excepción y construía a sectores de la población como enemigos internos, se organizó dicha celebración que contó con la participación de la sociedad civil: académicos, iglesia, empresariado, prensa, etc.

A partir de 1983 y con la recuperación del sistema democrático empieza a gestarse un cambio en las perspectivas académicas para el abordaje, desde la historiografía, la antropología social, la arqueología y la etnohistoria del estudio de los pueblos originarios y de la histórica relación con los procesos de colonialismo y de construcción estatal en Argentina.

En el presente podemos identificar que hay una tendencia en dos direcciones. Las mismas no necesariamente serían antagónicas pues incluso algunos autores se han posicionado sucesivamente en una u otra. No obstante, han quedado definidas en algunos puntos específicos del debate como perspectivas enfrentadas.

Por un lado, encontramos trabajos que identifican como momento de cambio $\mathrm{y}$ de quiebre en las relaciones sociales al contexto de sometimiento e incorporación estatal de los territorios y pueblos originarios hacia fines del siglo XIX. Estos han utilizado en buena medida el concepto de genocidio como herramienta conceptual para identificar no solo acciones bélicas, resistencias armadas, estrategias estatales y de los pueblos originarios sino también, y fundamentalmente, para no cerrar el análisis con ellas. Es decir, han presentado una periodización amplia en la cual el foco esta puesto en las estrategias del biopoder, los procesos de nuevas comunalizaciones, la articulación con discursos e imaginarios nacionales y las políticas en contextos posgenocidas. El encuadre metodológico ha implicado el trabajo con distintos tipos de archivos 
1. La estructura del artículo obedece al hecho de que al debate sobre la utilización del concepto de genocidio le ha seguido la crítica de quienes han sostenido, en cambio, el uso del concepto de guerra. históricos, públicos y privados, pero también la incorporación de la memoria social en sus registros orales y escritos.

Por otro lado, muchos autores han identificado en los eventos de referencia un momento particular dentro de un proceso con mayor continuidad que de cambios trascendentes. En el análisis ha primado la utilización del concepto de guerra en sus diferentes variantes. Dentro de estas, la idea que más ha traccionado ha sido la de comprender un ciclo de guerra en la cual dichos eventos serían un momento. Se ha planteado como una guerra social total, por recursos o de producción de soberanía. Se sostiene la imposibilidad de separar dicotómicamente las partes que se enfrentan en la contienda y se hace hincapié en los procesos de popularización; es decir, proponen colocar el foco en las complejas tramas de relación indígena-criolla que se despliegan desde mucho antes y trascienden los eventos de referencia. En cuanto a lo metodológico se ha procurado desentrañar las redes de relación a través de los enfoques microhistóricos, fundamentalmente mediante el trabajo con distintos tipos de archivos.

Mi propuesta aquí parte de pensar en algunas de las principales líneas teóricas que están detrás de la actual construcción como objeto de estudio de estos procesos. Especialmente en cuanto al devenir que han tenido a lo largo del siglo XX las definiciones del concepto de guerra y la génesis del concepto de genocidio.

Me detendré luego en algunas de sus aplicaciones para el caso de referencia -los procesos de sometimiento e incorporación estatal de fines del siglo XIX sobre el área de Pampa y Patagonia- a través del análisis de tres grandes cuestionamientos y tipos de preguntas que se han realizado a aquellos trabajos que lo han abordado en términos de genocidio. ${ }^{1}$ En primer lugar, en relación con el supuesto de que dichos enfoques para el estudio de este tipo de procesos habrían planteado una dicotomía entre estado y sociedad indígena, homogeneizándolos y deshistorizándolos en su constitución y agencia. Un segundo planteo, que se desprende del primero, sería la identificación de una y otra parte como victimarios y víctimas, negándose así la agencia indígena y los procesos de popularización o hibridación. Un tercer planteo refiere a la ex-temporalidad del concepto genocidio para analizar eventos previos a su elaboración y a la elección de otros posibles términos, como guerra social, asimétrica o de producción de soberanía. Finalmente, se evaluarán las implicancias que tienen tanto el uso como la negación del concepto de genocidio para este tipo de estudios históricos.

\section{Sobre la historia de los conceptos}

Desde el contexto de los eventos referidos como conquista de las Pampas, Patagonia y Araucanía de fines del siglo XIX se desplegaron procesos de consolidación estatal en el cono sur americano. Procesos en los cuales se desarrollaron, en diferentes contextos, particulares disputas y construcciones hegemónicas en torno a las lecturas sobre aquellos hechos. Desde una inicial interpretación en términos de proceso civilizatorio que realizara el mismo sector político que capitalizó los eventos del sometimiento de los pueblos originarios, hasta las actuales discusiones en torno a la violencia fundacional del estado en los casos argentino y chileno que involucra en el presente a diferentes sectores de la sociedad. El debate y discusión historiográfica al que nos referiremos en este artículo se inscribe también en este proceso en el cual 
se confrontan ideas y definen políticas concretas que involucran, fundamentalmente, a los pueblos originarios.

En efecto, la historia de los estados a lo largo del siglo XX ha estado acompañada por las profundas redefiniciones conceptuales en la necesidad de dar cuenta de los distintos procesos que se desplegaron en el período. En particular, aquí nos ocupan aquellas relacionadas con la descripción de las nuevas formas de violencia estatal y que han llevado a la redefinición de conceptos como guerra ya la aparición de otros como genocidio, para analizar y dar cuenta de la violencia desplegada en las relaciones interestatales, coloniales y de subalternidad. Como señala Paul Bartrop, el siglo XX introdujo conceptos que no existían en la conciencia humana, como movimientos políticos de masas, medios de comunicación masiva y muerte masiva (Bartrop, 2002: 519). Sin pretensiones de abarcar aquí todo este proceso de desarrollo conceptual me interesa destacar en este apartado algunos autores e ideas que han sido centrales y que han influido en las actuales discusiones historiográficas sobre el sometimiento de los pueblos originarios en el caso argentino. Más adelante, en los subsiguientes acápites, abordaremos las principales propuestas que los/ as autores/as generaron para abordar el caso de referencia de este artículo.

Mientras que el concepto de genocidio comienza a utilizarse a mediados del siglo XX, el concepto de guerra tiene una extensa y compleja historia. En relación con el debate que aquí nos convoca, enfocamos en algunas de las formas en que se ha definido la guerra en relación con la construcción de la otredad irredimible. Dado que es en este punto donde el concepto de genocidio ha venido a representar una definición conceptual con pretensión de mayor precisión. Otredad que se vincula con la construcción del poder soberano y la seguritización de la vida social.

En su recorrido a través del uso de los conceptos, Ricardo Laleff Ilieff brinda ejemplos de la profundidad histórica de esta violencia hacia el otro extremo, como la guerra con los bárbaros en las polis griegas o la guerra justa medieval frente al enemigo infiel, en los que el enemigo era quien vivía de una forma diferente a la propia. La guerra se llevaba a cabo, entonces, contra el otro que no compartía la misma paideia, aquel que representa una oposición existencial (Laleff Ilieff, 2012: 3).

En cuanto a la relación entre guerra y poder soberano, el mismo autor sostiene que en Thomas Hobbes -quien identifica al estado de naturaleza como un estado de guerra- el miedo a la anarquía aparece como elemento central de la forma política moderna. Solo cuando aparece el estado, sostiene, puede existir el miedo a la anarquía. Es el estado quien alimenta el temor al caos a fin de evitar la desobediencia y la guerra civil; y este miedo es el que moldea y fija los contornos de la autoridad política (Laleff Ilieff, 2012: 5-6).

Sin dudas Carl von Clausewitz ([1832] 1968) ha sido el referente para pensar desde el siglo XIX la guerra entre estados. Su propuesta establece un vínculo entre los conceptos de guerra y política permitiendo superar la idea de la guerra como la violencia de un estado pre-social. Para este autor la guerra es una de las posibilidades de la política, no siendo posible por tanto separar una guerra real de sus orígenes y su fin, que en definitiva es imponer la voluntad propia al otro. ${ }^{2}$

Para referirme entonces a la diferenciación entre tipos de violencia estatal es que entiendo como significativa la idea de excepción vinculada al poder
2. Raymond Aron sostenía que si "los estados actúan políticamente por la violencia", las modalidades de esta última no definen que unas guerras sean menos políticas que otras (Aron, 1989: 105, en Anzaldi, 2011: 47). 
3. Con respecto a Schmitt y la idea de la excepción y su relación con la norma y el sentido de lo anormal es necesario remarcar su relación con el contexto de surgimiento del nacional socialismo en Alemania. Ver, entre otros, a Joseph Bendersky (1983). Para Schmitt el estado de excepción no significan poderes extraordinarios sino una defensa de la norma y de la constitución de ataques desde fuera y adentro. soberano que, planteada desde distintas perspectivas, ha dado lugar a la diferenciación y la distinción que aquí nos convoca entre los conceptos de guerra y genocidio. En especial la idea de excepción y su relación con la norma.

El filósofo nazi Carl Schmitt sostenía que el estado de excepción se basa en la necesidad de proteger a la constitución en contra de un ataque desde afuera o desde adentro; esto es, en contra de los enemigos internos o externos (Schmitt, [1932] 1963: 12). La idea de la excepción es lo opuesto a la norma y está conectada a la idea del poder soberano, aquel que tiene el poder de decidir acerca de la excepción (Samir Benavides, 2006: 129). Al decidir sobre la excepción el soberano está decidiendo sobre la norma. La excepción está entonces en el origen de la norma. ${ }^{3}$ Giorgio Agamben (2010), en la misma dirección, señala que el soberano que está fuera del derecho decide que no hay un afuera del derecho.

El estado de excepción puede generalizarse como parte del paradigma de la seguridad, como una técnica normal de gobierno. Así, para Agamben (2010), la metáfora de la guerra se convierte de esa manera en la forma central para la discusión de la excepción, como veremos más adelante con los ejemplos de la redefinición del concepto de guerra en relación con el terrorismo en el presente.

Pero detengámonos en cómo la idea de los dos tipos de enfrentamiento se entiende ya en el siglo XX. Schmitt distinguía, por un lado, entre aquellos desarrollados entre amigo y enemigo (hostes) y, por el otro, entre amigo y contrincante (inimicus). La primera distinción es una categoría política que conduce al reconocimiento del otro como otro; esto es, conduce al reconocimiento del otro como alguien con igual valor que el mío. Basado en esto, el enemigo tiene que ser enfrentado en la batalla política, cuyo extremo es la guerra (Samir Benavides, 2006: 136). Para Schmitt el único pluralismo que debe ser autorizado es aquel entre Estados, pero dentro del Estado no se debe admitir enemigos sino contrincantes -recordemos su relación con el nacionalsocialismo. Esto es, dentro del Estado el soberano no reconoce iguales y por ello el oponente es tratado como un contrincante y por eso mismo debe ser destruido. Este es el caso de la guerra civil. Si el soberano reconociera la igualdad del oponente, la guerra civil sería una guerra entre iguales y por tanto una guerra en la que el oponente tiene acceso a la territorialidad y a la representación en condiciones de igualdad a nivel internacional. En la guerra civil el soberano es uno y el contrincante tiene que ser destruido.

La concepción de guerra civil y su diferenciación de la guerra entre estados tiene obviamente sus variantes. Como señala Nicolás Iñigo Carrera, si bien no hay definiciones de guerra en los autores clásicos del socialismo científico -Marx, Engels, Lenin y Gramsci-, estos dan por supuesto la idea de guerra civil, o guerra social, entre capital y trabajo como eventos de extrema crueldad; la cual es resultado del abandono de todo respeto por las convenciones de la guerra entre estados. La guerra civil abierta es la lucha armada entre dos partes del pueblo y, por ende, es más compleja e imprecisa que la guerra entre naciones (Iñigo Carrera, 2017).

La guerra es parte de las relaciones internacionales y por ello no puede ser sometida a sanción. Pero el concepto de guerra total intensifica la distinción entre amigo y enemigo, convirtiéndose en una situación no de guerra externa sino en una de guerra civil; es decir, una basada en la distinción entre amigo y contrincante. ${ }^{4}$ En esta guerra, no es posible distinguir entre combatientes y no combatientes, o entre estado enemigo y población del estado enemigo.
4. Como señala Bassford (1994) el de guerra total es neamente atribuido a Clausewitz quien, por el contrario, sí habla de guerra absoluta como aquella en la cual la política no tiene lugar, algo que él mismo ve como imposible. E concepto de guerra total es también atribuido a Erich von Ludendorff -mariscal alemán de la primera guerra mundial- quien a diferencia de Clausewitz la concebía como la total subordinación de la política a los esfuerzos de guerra (Bassford, 1994: cap. 2). 
Queda bajo la potestad del soberano determinar quién es el enemigo y quién el contrincante. Él determina cuándo hay guerra y cuándo paz, esto es, en el orden internacional, después de la juridificación de la guerra hemos llegado a una situación de estado de excepción permanente (Samir Benavides, 2006: 140).

Por lo tanto, los procesos de construcción estatal desde fines del siglo XIX y a lo largo del XX han sido el contexto que ha llevado a la redefinición conceptual para describir con mayor grado de especificidad los tipos de violencia estatal. También cabe incluir los procesos de expansión colonial y exterminio étnico, entre sus muchas variantes, especialmente aquellos casos en los cuales no ha existido el reconocimiento de un otro con voluntad, o como sujeto de derecho; es decir, hacia el cual solo se produce violencia con el objeto de su eliminación, su dejar de ser. Se trata de casos en los cuales la violencia ejercida podría no ser pensada como "política por otros medios". ${ }^{5}$

En relación con este tipo de violencia, en especial con el holocausto, es que el concepto de genocidio adquirió forma a mediados del siglo XX. Al mismo tiempo, y en relación con dichos procesos, la reflexión jurídica sobre la guerra llevó a una redefinición de los convenios internacionales y su aplicación, especialmente luego de la segunda guerra mundial. ${ }^{6}$

En ambos casos, entonces, las redefiniciones conceptuales lejos están de ser comprendidas como disquisiciones teóricas sino que han estado en directa relación con la aplicación concreta de sanciones jurídicas y la implementación del derecho internacional.

A mediados del siglo XX la reflexión teórica sobre la guerra ya no puede obviar la muerte masiva de las expansiones coloniales, las políticas de limpieza étnica, el holocausto y la amenaza de la guerra nuclear de aniquilamiento. Con el fin de la Segunda Guerra la recientemente creada Organización de Naciones Unidas (ONU) establece como una de sus prioridades producir un artefacto jurídico de aplicación internacional que castigue y prevenga los crímenes de lesa humanidad. ${ }^{7}$ Se trata, por lo tanto, de un debate político que lleva hacia 1948 a la construcción de un nuevo concepto jurídico, el delito de genocidio.

Con el mismo se identifican y se piensan los eventos contemporáneos que precisamente se procuran erradicar. Su creador, Raphael Lemkin, era un jurista polaco, superviviente del nazismo, que por más de una década venía desarrollado avances hacia la tipificación -como parte del derecho internacional-de distintos tipos de crímenes de lesa humanidad. En 1944 publica su primera definición de genocidio, ${ }^{8}$ término que fue utilizado en los procesos de Nüremberg de 1945 contra la jerarquía nazi -aunque no aparece en las condenas. Si bien en dicha obra Lemkin hace referencia explícitamente al régimen nazi, desde su perspectiva el concepto no refería solamente a los crímenes del nazismo sino que tenía presente otros tipos de acciones estatales, como la persecución del pueblo armenio en el Imperio Otomano, la expansión colonial sobre África y también las políticas norteamericanas con los pueblos originarios de fines del siglo XIX. Como señala Mariano Nagy, en su artículo de este Dossier, desde 1946 la ONU adopta el término y comisiona a los juristas Henri Donnedieu de Vabres, Raphael Lemkin y Vespasien Pella para preparar un proyecto de convención sobre genocidio. El borrador elaborado por dicha comisión mencionaba tres tipos de actos de genocidio: físicos, biológicos y culturales. Su definición no se limitaba a las medidas destinadas a la eliminación física sino que también involucraba la forma de vida del grupo y sus expresiones religiosas y culturales. Por lo tanto, el concepto nace con profundos rechazos dentro
5. Si bien es posible argumentar, como lo plantea Aron (ver nota al pie 2), que aún la violencia genocida es política, nuestro argumento recurre a la necesidad de discriminar entre lo que puede ser llamado política y aquello que no -siguiendo a autores como Rancière (1996) y su distinción, por ejemplo, entre política y policía.

6. Los Convenios de Ginebra se realizaron en 1864, 1906, 1929 y 1949.

7. Para los antecedentes de la Declaración de la Convención de las Naciones Unidas sobre el crimen de genocidio de 1948 , como los tratados de protección de minorías del periodo entreguerras, ver el artículo de Mariano Nagy en este Dossier.

8. La obra de Lemkin (1944) se tituló Axis Rule in Occupied Europe. 
9. La autora también se refiere a estos tres momentos como: "la marcación de la víctima, la violencia abierta y los efectos de la misma", ver artículo de Pilar Pérez en este Dossier. de la misma asamblea de las Naciones Unidas y de la comunidad de juristas. En efecto, como describe Nagy, en su definición aprobada en 1948 fueron excluidas la noción de genocidio cultural y la mención a grupos políticos como una de sus posibles víctimas. No obstante, el proceso evidencia las distintas formas de pensar y nombrar políticas estatales, relaciones y prácticas sociales en las cuales desde una estructura estatal y desde la sociedad civil se operan medidas destinadas al aniquilamiento total o parcial de un grupo minoritario, étnico, cultural o político.

Con posterioridad, el concepto de genocidio fue redefinido por distintos autores incluyéndose casos históricos específicos y procesos más generales como el colonialismo y el desarrollo económico. En especial se contempló la relación de estados y pueblos indígenas, pero también la acción de individuos, que participan en los procesos de colonización y en la construcción de una nueva sociedad basada en un genocidio. En esta dirección se destacan los planteos de Fein (1984), Moses (2008) y Wolfe (2006). En gran medida, la reflexión teórica buscó tomar distancia tanto de la definición jurídica, para pensarlo como concepto analítico, como también del caso específico del holocausto. No obstante, dichos desarrollos también acompañaron diferentes contextos políticos en un proceso que ha llevado a redefinir el espacio jurídico. Desde la redacción de informes especiales como el de la comisión Whitaker (1985), la creación de tribunales internacionales como en los casos de la ex Yugoeslavia (1993) y Ruanda (1994), la discusión del Estatuto de Roma (1998) y finalmente la puesta en funcionamiento de la Corte Penal Internacional (2002). En cuanto a la historia y las redefiniciones del concepto me remito a los trabajos de Mariano Nagy y Pilar Pérez que forman parte de este Dossier. El trabajo de Pérez, en particular, identifica claramente los principales ejes que tomaron las sucesivas redefiniciones del concepto desde las ciencias sociales en la búsqueda de analizar las sociedades en su conformación histórica, las características sociológicas de los perpetradores, las tecnologías de violencia, sus vinculaciones políticas y económicas, las diferentes formas de singularización de las víctimas y, finalmente, los observadores y testigos.Por último, Pérez sintetiza, a través de los aportes de Stanton (1998) y Feierstein (2007), los objetivos de los estudios comparativos sobre genocidio, los cuales en el análisis de sus diferentes etapas han coincidido en plantear al menos tres momentos: los pasos que conducen a la violencia abierta, la violencia genocida en sí misma y el período de negación. ${ }^{9}$

Aunque como concepto jurídico ha recibido muchas críticas -en especial por su definición de víctimas y por el requisito de intencionalidad-aquí me interesa enmarcar el momento y objeto por los que el concepto tiene su origen. Más allá de ser parte de la búsqueda por generar elementos de sanción y prevención de este tipo de delitos, desde sus inicios el concepto nace como un instrumento histórico descriptivo. De la misma forma, nuestros debates académicos no se sitúan por fuera de los procesos de relación entre estados y minorías sociales y la disputa política de nuestro contexto. En otras palabras, la disputa en 1948 en torno a la exclusión de los grupos políticos como víctimas de genocidio, no es menos política que los debates sobre la aplicabilidad del concepto para los crímenes de la última dictadura o en relación con los pueblos originarios en el caso argentino.

Como han señalado la mayor parte de los autores que abordan la guerra, los eventos del siglo XX presentan un quiebre en la concepción clásica de la misma, siendo necesario redefinir y pensar nuevos conceptos. En efecto, el concepto de genocidio nace como sinónimo de crimen de guerra para adquirir mayor 
especificidad al punto que ya no estará necesariamente relacionado con la guerra.

Según Schmitt con la guerra fría se rompen los pilares conceptuales que limitaban y contenían la guerra ([1932] 1963: 9-10). Pero no sólo la guerra fría y la amenaza del aniquilamiento global, sino los procesos revolucionarios y de descolonización convocaron a esta reflexión conceptual.

Para autores como Schmitt amerita utilizar otros conceptos para referir a este tipo de conflictos, como lo es el de guerra irregular. Con el mismo refiere a la guerra chino-japonesa de 1932, la misma segunda guerra y la de Indochina. Encuentra allí la existencia de una resistencia autóctona, esencialmente defensiva, que el pueblo de un país le opone a la invasión extranjera. El partisano, que para la guerra clásica no era más que un "irregular" y objeto de la policía -mientras el ejército combatía al enemigo-, ha devenido en una figura clave de la guerra revolucionaria mundial. Por otro lado, las conceptualizaciones de guerra irregular y sus variantes -como guerra irrestricta o asimétrica- pueden ser comprendidas como guerra popular prolongada como la define Mao Tse-tung ([1938] 1976); es decir, una estrategia militar que procura mantener el apoyo de la población y atraer al enemigo al interior donde la población puede accionar por la movilidad de una guerra de guerrillas.

Otros autores, como William Lind, han propuesto conceptos como guerra asimétrica o híbrida. Lind sostiene que el término surge para identificar organizaciones y grupos terroristas o criminales que enfrentan a estados, sea el propio o no, obedeciendo a motivaciones ideológicas, étnicas, religiosas, económicas, particulares o privadas. Este se define como un enfrentamiento asimétrico entre un actor estatal y otro no estatal y su propuesta apunta a incluirlo dentro del concepto de guerra. Hacia 1986, Lind desarrolla este concepto en conjunto con un grupo de oficiales del cuerpo de infantería de marina estadounidense. Su propuesta es conocida como guerra de cuarta generación ${ }^{10}$ y en ella se incluyen otros términos como guerra de baja intensidad y guerra sucia. De acuerdo a estos autores, la guerra asimétrica se caracterizaría por organizaciones y grupos terroristas que "actúan bajo un sistema de valores en que la violencia, las atrocidades y la muerte son un modo de vida y que, como tal, es radicalmente diferente al del mundo occidental" (Lind et al., 1989). El objetivo de esta guerra asimétrica sería el colapso moral del enemigo más que su destrucción física, alterar la forma de vida de la sociedad del enemigo más que lograr conquistas territoriales. Por esta razón, en este tipo de conflicto, los blancos se encuentran en elementos representativos y emblemáticos de la cultura del adversario (Lind et al., 1989: 11).

Por su parte Qiao Liang y Wang Xiangsui (1999) han planteado el concepto de guerra irrestricta identificándola como el futuro tipo de enfrentamiento: uno en el cual frente a la enorme asimetría de poder solo será posible identificar insurgentes que utilizarían objetos de la vida cotidiana como nuevas e inesperadas armas. ${ }^{11}$

De esta forma, encontramos que han sido los altos mandos militares de las fuerzas armadas norteamericanas los que emplearon el término guerra híbrida o asimétrica. Especialmente durante sus testimonios ante el Congreso de los Estados Unidos, entre 2008 y 2010, para describir los métodos usados por sus adversarios en Iraq y Afganistán, y señalando que son estos a los que probablemente deban enfrentarse las fuerzas de los Estados Unidos en futuros conflictos (González, 2017). Es decir, al definir a la guerra como asimétrica o hibrida
10. Sobre guerras de cuarta generación ver Martín Van Creveld (1991).

11. La obra en español se tituló Guerra más allá de los límites, pero en los Estados Unidos se publicó bajo el antojadizo y polémico título Unrestricted Warfare: China's Master Plan to Destroy America. 
12. El comunicado oficial de la Casa Blanca se refirió a los prisioneros en Abu Ghraib y otras prisiones en Irak y Guantánamo como combatientes enemigos a los cuales no se les aplicó la tortura sino "técnicas agresivas de interrogatorio", también llamadas "técnicas de interrogatorio mejoradas" .Disponible en Internet: https://www.montevideo.com. uy/Noticias/El-martes-se-conocerainforme-sobre-tecnicas-agresivasde-interrogatorio-por-parte-dela-CIA-uc255220? plantilla=1391. Consultado el: 7 de julio de 2018

13. El uso alternativo de estos conceptos no ha sido explicado por los autores. La definición de guerra social, a secas, toma distancia de lo que hemos planteado en este acápite en relación con las definiciones de guerra civil y guerra social. se legitima también una "estrategia híbrida", en la que un estado recurre a todos los medios que tiene a su alcance, además del instrumento militar, para alcanzar los objetivos. Allí se legitiman Bagram, Guantánamo, Abu Ghraib. ${ }^{12}$

Como señala Raúl Sohr (2009), en las últimas décadas el concepto de guerra asimétrica ha ganado notoriedad para describir el choque entre fuerzas regulares e insurgentes en el cual se miden bandos con fuerzas muy dispares. Por ejemplo, para describir las operaciones desarrolladas por Israel en la Franja de Gaza.

Samir Benavides señala que para Schmitt el nuevo orden global es el resultado de la juridificación de la guerra. El mundo es lanzado a una guerra civil de carácter global donde no hay enemigos sino criminales, la guerra es el modo de sancionarlos y hacer que desaparezcan. Estados Unidos se convierte en el soberano global con el poder para decidir acerca de la paz y de la guerra, acerca de la norma y de la excepción (Samir Benavides, 2006: 141).

Según Laleff Ilief uno de los rasgos de esta guerra contemporánea es la discriminación del enemigo al presentarlo como otro antagónico cultural (2012: 9). En ella priva el paradigma de la seguridad, no quedando en claro cuáles actividades son seguritistas y cuáles militares.

Un análisis general de este breve recorrido marca la directa relación que existe entre los procesos, contextos y casos históricos, y las redefiniciones conceptuales. Siendo que los eventos como el sometimiento, conquista y ocupación de los pueblos originarios y sus territorios forman parte de los procesos de consolidación estatal la pregunta que gira en las siguientes páginas es en relación con la conveniencia de utilizar uno u otro de los conceptos arriba señalados.

Encontraremos en los distintos autores la elección de conceptos propios como guerra social total (Escolar et al., 2015: 224), construido como adaptación del término proceso social total de Raymond Williams (1988). Estos autores también lo han utilizado solo como guerra social, ${ }^{13}$ con el cual se identifica un enfrentamiento entre partes que son heterogéneas dado un proceso de popularización criollo-indígena en el cual una multiplicidad de actores con valores y prácticas compartidas se relacionan en estructuras híbridas. De allí que estos autores también utilicen los términos de guerra de recursos y guerra de producción de soberanía (Vezub, 2009; Escolar et al., 2015; Sourrouille, 2017). Estas dos últimas definidas en relación con las estrategias de las operaciones bélicas y con sus objetivos.

Otros autores han utilizado el concepto de guerra asimétrica con el objeto de incorporar al análisis de la guerra casos que han sido excluidos, por el hecho de representar enfrentamientos entre estados y formaciones no estatales, al tiempo que para enfocar en las estrategias de resistencia (Richard, 2015; De Jong, 2018). Por su parte, encontraremos propuestas que utilizan el concepto de genocidio desde su definición jurídica (Díaz et al., 2007; Delrio et al., 2010), y también como concepto analítico, a partir de las redefiniciones mencionadas de Feierstein en cuanto a prácticas sociales (Papazián, 2007; De Jong, 2018) o Wolfe (2006) y Moses (2008) vinculadas a los procesos de construcción de una sociedad resultante de dicho genocidio y a la participación de individuos y distintos estamentos de la sociedad civil como victimarios (Delrio y Pérez, 2018).Como el lector apreciará, en muchos casos los autores han realizado sucesivas y distintas elecciones y también propuestas para relacionar ambos tipos de conceptos (De Jong, 2018). 
Sin dudas el debate aquí planteado participa en otros más amplios a los que se aporta desde el caso. Nos preguntamos, en definitiva, cómo comprender la violencia fundante de los estados contemporáneos. Estas elecciones pueden decir mucho de las formas de construcción de hegemonía tanto en el proceso de construcción de las matrices estado-nación-territorio como las vigentes. Al mismo tiempo hacen visible el poder perfomativo que han tenido y tienen las formas de narrar y clasificar el pasado.

En los siguientes apartados se abordarán tres tipos de preguntas, más específicas, que han sido planteadas en el diálogo entre las distintas perspectivas de análisis pero anclando el debate en la conveniencia del uso de los conceptos de guerra y genocidio y a la forma en que los mismos han sido aplicados en el caso del sometimiento estatal de los pueblos originarios en Argentina. Debate a veces explícito, otras implícito.

\section{El genocidio como transformación de las relaciones sociales}

Una crítica realizada a los trabajos que utilizan el concepto de genocidio es que los mismos tenderían a concebir una dicotomía entre estado y sociedad indígena, comprendiendo a ambos como homogéneos y esencializados. Especialmente se los acusa de reificar, por un lado, al estado como un Leviatan que avanza sobre espacios vacíos; $y$, por el otro, a las sociedades indígenas al presentarlas como cultural y socialmente homogéneas. ${ }^{14}$

Para abordar esta discusión tomaremos los dos tipos de periodización de las relaciones entre formaciones estatales y pueblos originarios que han sido planteados desde los estudios que utilizan los conceptos de genocidio y de guerra.

Como señala Papazián (2007), refiriéndose al genocidio del pueblo armenio, el uso del término refiere a un momento de las relaciones sociales en las cuales se produce un replanteo de las mismas, implicando tanto desestructuración como estructuración de nuevas relaciones e identidades. ${ }^{15}$ Entendiendo al genocidio como una práctica social (siguiendo a Feierstein, 2007) y no sólo como concepto jurídico, el autor identifica distintos momentos o etapas que llevan desde la construcción negativa del otro a la implementación de acciones directas de violencia y finalmente a la negación y realización simbólica. Para el caso de Pampa y Patagonia la pregunta sería entonces si es posible identificar una ruptura de tales características y cuál sería la periodización de este proceso. En esta dirección encontramos la realizada por Nagy y Papazián (2009 y 2018) en cuanto a la utilización de la Isla Martín García como campo de prisioneros entre 1871 y 1886; el estudio de la llamada última frontera que recorría el oeste de la actual provincia de Buenos Aires también realizado por Nagy (2013) o la descripción del avance militar sobre norpatagonia y la formación de campos de concentración por parte de Pérez (2016). A partir de los trabajos antes mencionados y otros propios hemos propuesto una periodización general que identifica tres momentos: la producción del otro (1872-1878), el despliegue de violencia sistemática (1878-1890) y la construcción de un nuevo orden social, desde1890 en adelante (Pérez y Delrio, 2017). En cuanto a la producción del otro como amenaza, se identifica un quiebre en la década de 1870 hacia la construcción del estereotipo del "indio malonero". Este homogeneizó discursivamente la imagen del indígena atribuyéndosele dos elementos claves: la extranjería -un supuesto origen chileno- y su salvajismo antisocial -asociando el término malón con el de robo. Esta perspectiva particular, que identifica a los llamados indios maloneros como una amenaza a los bienes, las personas
14. Escolar et al. (2015: 224) afirman, por ejemplo, discutir “con la visión (llamativamente compartida por la mayoría de los defensores y críticos de las campañas) de una maquinaria estatal que avanza sobre una cartografía social vacía o vaciada por la fuerza todopoderosa y homogénea de las armas del Estado".

15. Siguiendo a Feierstein (2007), Papazián (2007) aborda el término en tanto práctica social llevada adelante por el Estado que desestructura y reestructura relaciones sociales al interior de una sociedad heterogénea, "creando nuevas subjetividades e identidades donde antes existía una relación de vecindad conflictiva". 
16. En relación con los tratados, sus textos y el poder perfomativo de los mismos véase, entre otros, Briones y Carrasco (2000), Levaggi (2000), Tamagnini y Pérez Zavala (2002); con respecto a los debates parlamentarios Lenton $(1994,2005)$ y Navarro Floria (2001) y sobre los debates en la prensa, Fridman (1979).

17. Para una descripción de estas acciones de violencia sobre la población originaria véanse Nagy (2013), Pérez (2016), Delrio et al. (2018).

18. En anteriores trabajos hemos descripto cómo se fueron dando los cambios en la documentación argentino y chilena a nivel del discurso en la utilización de términos como: indios argentinos/chilenos, salvajes, rebeldes y asilados, en el transcurso de pocas semanas, incluso hacia marzo de 1883 (Delrio, 2005: 34-84). También hemos abordado las órdenes extendidas desde las jefaturas militares hacia sus subordinados para analizar los cambios que, en el contexto de 1878-1885, ven necesario marcarles para el tratamiento de los indígenas (Delrio, 2015).

19. El coronel Enrique Godoy cuestiona al mayor Peitado por haber tomado esa decisión aunque entiende su "móvil patriótico". Los regalos fueron entregados por el comerciante Fermín Viera en septiembre de 1884. (AGN, Al, Contaduría nacional, Ministerio de Guerra, 1885 , L. 21, f. 68). y al mismo orden social nacional, se impone a finales de la década de 1870 . Deviene como teoría social hegemónica y establece una fuerte dicotomía en la cual los estereotipos son marcadamente homogéneos, opuestos y antagónicos. No sólo establece aquel del eliminable en aras del orden social nacional sino también el estereotipo del que podrá sobrevivir, a través, precisamente, de su dejar de ser indígena. Esta homogenización en la construcción del otro implica un borramiento del pasado de relación y se despliega en la década de 1870 a través de los acuerdos firmados con distintos caciques, debates parlamentarios, en la prensa y la publicación de textos académicos. ${ }^{16}$

El momento de violencia abierta sobre los pueblos originarios se superpone también a lo largo de la década de 1870, como lo referencian Nagy y Papazián (2009; 2018) en relación con el campo de Martín García, aunque es posible identificar un claro aumento hacia 1878 relacionado con las campañas militares desplegadas por el estado nacional sobre las pampas y el norte de la Patagonia. A partir de entonces, se multiplican las acciones sobre la población originaria -más allá de puntuales y por cierto escasos enfrentamientos armados. Me refiero a los sistemáticos ataques a tolderías y grupos de ancianos, mujeres y niños, su captura, concentración, deportación y distribución. ${ }^{17}$ La ruptura que representa este momento se manifiesta tanto a través del discurso como de prácticas y dispositivos hacia los grupos sobre los que opera el estereotipo. ${ }^{18}$ En 1884 el Mayor Roque Peitado es reprendido por sus superiores al intentar lograr una negociación con Inacayal y Sayhueque mediante la entrega de regalos. Su superior le advierte que dichas prácticas, comunes en todo el período previo, estaban prohibidas en adelante. ${ }^{19}$ No existía la posibilidad de negociar nada, solo la presentación del cacique con todos los suyos.

Finalmente identificamos un tercer momento que va desde el fin de las concentraciones, caracterizado por la realización simbólica de una nueva sociedad de colonos en la cual los derechos de estos se imponen sobre el principio de haberse afirmado la inexistencia de cualquier unidad sociopolítica y sociocultural indígena. El discurso que niega su existencia, en tanto pueblos, admite la supervivencia solo de personas que han dejado de ser parte de grupos e incluso indígenas. El mismo se materializa en toda la política de tierras y colonización en la región de norpatagonia desde entonces. En el análisis de los accesos a la tierra por parte de sujetos indígenas se manifiesta claramente esta exclusión. El estado no los reconoce como sujetos que puedan contratar, la sola identificación como tales es razón de su exclusión o desalojo. Esto ha sido analizado tanto desde la normativa específica y las políticas gubernamentales como desde el corpus de los expedientes e informes de las inspecciones de tierras (Delrio, 2005; Pérez, 2016).

En una dirección similar, discutiendo la aplicación de conceptos como guerra, genocidio y resistencia para el período, Ingrid de Jong (2018) propone comprender al genocidio como modificador de las relaciones sociales en un proceso de relación e imposición de una "lógica del Estado", caracterizada por el monopolio legítimo de la coerción, sobre la "lógica del parentesco" basada en la reciprocidad y en las jerarquías derivadas de las relaciones de parentesco indígenas. Proponiendo un enfoque en las estrategias de resistencia indígena De Jong marca también el cambio profundo entre una política de frontera hasta fines de la década de 1870, en la cual intervienen las lógicas estatales y de parentesco o indígenas, caracterizada tanto por la diplomacia como el enfrentamiento, a un momento de imposición o guerra asimétrica que conduce a las prácticas sociales genocidas del estado. 
Desde estas investigaciones históricas, enfocadas en la política de fronteras, la militarización, el discurso, las políticas sociales y las disputas de recursos, se han descripto las elaboraciones ideológicas, las violencias y las relaciones sociales genocidas en un proceso de construcción estatal en el cual han sido identificados distintos momentos. Se han descripto diferentes mecanismos a través de los cuales, desde agencias estatales y de la sociedad civil, se operó hacia el objetivo común de la imposición de nuevas relaciones sociales que excluyeran y negasen la persistencia de cualquier tipo de unidad sociopolítica o sociocultural indígena.

Autores que, por el contrario, proponen entender el proceso han señalado que la propuesta en términos de genocidio implica una homogeneización del estado. Estos identifican un alto grado de continuidad entre las políticas de frontera previas y las campañas de avance de 1878-1885, e incluso con los procesos posteriores a las mismas. ${ }^{20}$ Dicha continuidad estaría evidenciada, por ejemplo, por la existencia del reclutamiento de "escuadrones indígenas" y la participación de los llamados "indios amigos" en dicha política. Así, se destaca la participación de estos y, aún más, nuevos cuerpos indígenas en el desarrollo de las llamadas campañas al desierto. Como resultado, este proceso habría implicado tanto estructuras militares híbridas (Escolar et al., 2015: 224) como una subjetividad "criolla" compartida (Vezub, 2013: 349). Al identificar procesos de popularización o la condición híbrida de las identidades indígenacriollas (Escolar, 2013), previas a las campañas de sometimiento, en su devenir de más larga duración se minimizaría la importancia dada al momento de sometimiento estatal como uno de cambio. En breve, se propone que las campañas militares del período 1878-1885 forman parte de un "ciclo de guerra" que habría comenzado mucho antes y finalizaría incluso años después con las entregas de tierras a algunos caciques indígenas.

Estos argumentos ponen el énfasis en no esencializar las agencias estatales e indígenas y comprenderlas dentro de una relación dialógica en la que existen complejas tramas de redes sociales, políticas y económicas a ambos lados de las fronteras. Proponen una continuidad de la guerra que lleva a relacionar las acciones de 1878-1885 con otras previas: "así, entre los antecedentes antiguos de la Campaña del Desierto están la expedición del gobernador de Buenos Aires Martín Rodríguez de 1824 y, muy especialmente, las operaciones que condujo Juan Manuel de Rosas en 1833 y 1834". La idea de continuidad aparece reforzada cuando, no obstante, queda la pregunta sobre la especificidad de cada contexto. Es decir, sobre qué tipo de estado-como idea, relación e instituciones- dan cuenta las distintas campañas, expediciones y acciones militares; es decir, cuáles son los cambios en las relaciones sociales y en el proceso de construcción estatal.

Especialmente, la propuesta de Escolar, Vezub y Salomón Tarquini (2015) sostiene que los eventos de fines de la década de 1870 y la de 1880 deberían ser entendidos como una guerra social total, de recursos y de producción de soberanía, pero al mismo tiempo formando parte de un mismo ciclo de guerra más amplio. Los autores sostienen que antes, durante y después, existió negociación y mutuos beneficios. Por ejemplo, refiriéndose a las campañas de Rosas de 1833-1834 señalan que su resultado tangible fue la expansión de las estancias en el sur de Buenos Aires y la pérdida de autonomía de jefaturas indígenas como las de Catriel y Cachul. Señalan, no obstante, que algunas se enriquecieron gracias a la multiplicación de negocios e intercambios que fomentaron los acuerdos con Rosas y, más en general, por el aumento de las migraciones, los mercados y la actividad ganadera que diversificaron la sociedad de frontera
20. "Las campañas militares del período guardan estrecha continuidad con prácticas, políticas y eventos específicos que venían desarrollándose desde muchos años antes y que en gran medida continuaron con posterioridad" (Escolar et al., 2015: 233). 
(Escolar et al., 2015). El planteo de un único ciclo de guerra supondría que este mismo tipo de lógica se aplicaría no solo a las campañas de 1878-1885 sino también a las décadas subsiguientes. De hecho, se deja abierta la cuestión al mencionar momentos posteriores del mismo ciclo, vinculados con entregas de tierras a caciques renombrados.

Este planteo abre preguntas en cuanto a la periodización. Mientras Escolar, Vezub y Salomón Tarquini (2015) hablan del fin del ciclo de la guerra hacia 1890, con el levantamiento de las concentraciones de prisioneros, Sourruille (2017), quien sigue a estos autores en su planteo de guerra social total, diferencia el pasaje de la guerra a la policía del desierto. No obstante, aclara que esta separación entre guerra y policía: "en definitiva, no se trata de procesos separados sino de una cuestión de perspectiva", según se oriente el foco hacia la rearticulación de las políticas indígenas o las estatales (2017: 90). La cuestión de las perspectivas lleva a que:

Nos preguntamos, en consecuencia, cuándo termina la guerra para Nahuelpan, y si acaso su derrota histórica -entendida como su desarticulación como entidad política, con la consecuente pérdida definitiva de la potestad del cacique de decidir sobre la distribución y uso de los predios al interior de la reserva- se produzca en un momento tan aparentemente tardío como el desalojo de 1937 (Sourruille, 2017: 96).

En su propuesta Sourruille plantea también que: "complementariamente, nos preguntamos cuándo termina la guerra de conquista para los colonizadores" (2017: 32). Coincidimos con estas preguntas en relación con la perspectiva propia de los involucrados. Esto nos lleva a otras cuestiones; la primera es la necesidad de involucrar en el proceso de investigación también a la memoria social mapuche-tehuelche, de los pobladores fiscaleros y de los "colonizadores", comprendiéndola como un complejo, heterogéneo y enorme corpus para

21. Algunos autores han criticado el uso de la memoria oral y sus narrativas, clasificándolas como memorias traumáticas (Escolar 2011). Itzkowitz, especialista del caso turco-armenio, es quizás el ejemplo más extremo de esta línea de argumentación. Llama a esta elección, de un trauma específico con el objeto de revitalizar la identidad étnica, como el desarrollo de una "mentalidad de víctima" que perpetúa la fijación del trauma de generación en generación (Itzkowitz 1972, citado por Theriault, 2001). Al igual que Itzkowitz, quienes argumentan contra el uso de dicho corpus oral proponen, en cambio, un relato historiográfico en el que no haya víctimas ni perpetradores, como señala Theriault (2001: 250) en contextos en que el grupo perpetrador no se arrepiente y se esfuerza en cubrir y atacar políticamente al grupo víctima.

22. Como los trabajos de Vezub (2009) y De Jong y Ratto (2008), entre otros. el trabajo historiográfico. ${ }^{21}$ Esta nos permitiría, por ejemplo, sopesar y comprobar si, como se señala arriba, una comunidad como la del boquete Nahuelpán recién en 1937 habría reconocido su pérdida de autonomía política solo por el hecho de que hasta ese entonces el cacique podía decidir por la distribución de predios al interior de una reserva. ¿No existió acaso una pérdida previa, en la reconfiguración de relaciones sociales por las cuales se ha limitado el acceso a los medios de producción y se pelea entonces solo por defender el margen de lo que ocurre en una reserva? ¿No es la situación de que exista un adentro y un afuera de la reserva un indicio para evaluar que ha existido un cambio sustantivo en las relaciones sociales? Un recorrido por los trabajos que han reconstruido la territorialidad de los grupos norpatagónicos en las décadas de 1860 y $1870{ }^{22}$ nos muestra comparativamente la significativa pérdida de autonomía, acceso a los recursos e inexistencia de cualquier reconocimiento político de los mismos luego de las campañas de 1880; más allá del fenómeno de eliminación física a partir de matanzas, expropiaciones, concentraciones y deportaciones masivas del periodo.

En breve, los enfoques que priorizan utilizar el concepto de guerra para los eventos del sometimiento e incorporación de fines del siglo XIX se proponen como superadores de dos tendencias. En primer lugar, de la tendencia a homogenizar y reificar al estado; no obstante, en algunos casos se llega a afirmar que lo que está en juego no es solamente un proceso de expansión militar de las fronteras sino un proyecto de ingeniería social (Vezub, 2009), en el cual habría planificación estratégica e información brindada por agentes de inteligencia, la combinación de las funciones estatales guerreras con las de policía, grandes 
movilizaciones, operaciones de control demográfico y territorial, desplazamientos sobre el terreno y restructuración violenta de la población (Escolar et al., 2015). En segundo lugar, proponen superar la tendencia a fetichizar al estado como un actor externo. Se sostiene que muchos de sus aspectos -burocracias, ejércitos, centralización, gobierno, administración de los territorios, archivos, formación de identidades nacionales- estaban presentes o eran construidos también de diversas maneras en el seno de las sociedades indígenas.

Esto último precisamente abre una segunda pregunta en relación a la agencia de la población sometida por los eventos de referencia.

\section{La agencia de las victimas}

Una segunda crítica que se ha realizado a la aplicación del concepto de genocidio está relacionada a una supuesta negación o invisibilización de la agencia de los pueblos originarios. Esto se produciría a partir de una homogeneización y victimización de estos colectivos -indiferenciando a sus iniciativas y aún más dejándolas en la sombra- al situarlos en una posición pasiva. ${ }^{23}$

Quienes proponen el concepto de guerra como marco interpretativo sostienen que resaltar las concepciones propias de la guerra, el ethos guerrero, de los pueblos indígenas, sus dispositivos de guerra, devolvería la agencia histórica de los mismos evitando caer en victimizaciones. Se sostiene que dicha agencia no sólo se basa en las resistencias sino también en "la contradictoria participación indígena en los procesos de formación estatal [...] independientemente de los resultados políticos (genocidio, incorporación, exclusión, invisibilización, resistencia, etc.)" (Escolar et al., 2015: 230).

En relación con la primera premisa encontramos como forzada la interpretación de que una descripción de prácticas genocidas implique dejar de lado las iniciativas de la población víctima de las mismas y sólo se la contemple en su pasividad. En relación con lo segundo, difícilmente también podamos llamar simplemente como guerra una reacción por las armas frente al poder avasallante de un estado genocida. Tengamos presente, por ejemplo, la resistencia en el gueto de Varsovia que retoma Nagy en este mismo Dossier. La construcción de la excepción de la población allí concentrada y la definición del proceso como genocida no están en discusión, como tampoco el recuerdo de las formas de resistencia frente al genocidio. De la misma forma, nos sentiríamos muy incómodos de analizar dicha resistencia en términos de los ethos guerreros de las partes contendientes o la contradictoria participación de los habitantes del gueto en la formación del estado nazi en Polonia.

La comparación no es capciosa ni forzada. El punto es si estamos dispuestos, o no, a definir al proceso como genocida. Dado que para algunos existen elementos suficientes para pensar el caso como un genocidio, acto seguido es porque, en efecto, se identifican víctimas y perpetradores. ¿Esto implica hablar de la agencia de estos últimos y la pasividad de los primeros? Recorriendo la producción de los autores que describen al proceso como genocida observamos que no. Por el contrario, precisamente ha sido la perspectiva y los modos de agencia de las víctimas los que han sido priorizados en estos enfoques.

El debate tiene muchas aristas, de hecho el enfrentamiento o resistencia armada también ha sido abordado por quienes utilizan el concepto de genocidio como es el trabajo de De Jong (2018), quien también utiliza en su periodización
23. Escolar et al. (2015: 243) hablan en términos generales de una "mirada subalternista que, desde su tipificación como grupos subordinados y victimizados, falla a menudo en desatender el análisis de las formas efectivas de agencia". 
24. Al respecto ver, entre otros, los trabajos de Tamagnini y Pérez Zavala (2002); Villar y Jiménez (2003), De Jong y Ratto (2009) y Vezub (2009)

25. Es interesante comparar el debate historiográfico argentino con otros casos, como el australiano; Moses (2008) señala que hacia la década de 1980 los historiadores reemplazaron el paradigma predominante de investigación situado entonces en el conflicto y el racismo en la frontera por otro que sostenía la sobrevivencia aborigen a través de una "acomodación" y cooperación con los colonos británicos

26. La formalidad de la cédula expresa "se le leyeron las leyes penales, pasó revista de Comisario y prestó juramento a la Bandera". Firman el documento Godoy y Peitiado. Este último firma su baja por inútil el 14 de abril de 1885 en Gral. Roca (AGN, Al, Contaduría nacional, Ministerio de Guerra, 1885, L. 23, f. 28).

27. AGN, Al, Contaduría nacional, Ministerio de Guerra, 1885, L. 25, f. 8 $1^{\circ}$ Batallón, $6^{\circ}$ Regimiento Infantería de Línea, septiembre de 1885.

28. Agradezco especialmente a Marisa Malvestitti por haberme facilitado el documento registrado por ella en el Instituto Iberoamericano de Berlín (Legado LehmannNitsche [j-783-4]) y su traducción del mismo, realizada junto a María Coña y Pablo Cañumil, que se publicará próximamente. En Chile, Llanquinao y Pozo Menares (2013) también publicaron una traducción. el término guerra asimétrica para referir a un momento del enfrentamiento entre un estado y sociedades segmentales. Los estudios sobre las relaciones fronterizas a lo largo del siglo XIX, han aportado muchos elementos para comprender cuáles han sido las estrategias de los estados en formación y las formas de organización sociopolítica de los pueblos originarios. ${ }^{24}$ La guerra de fronteras, las relaciones comerciales, los parlamentos y tratados descriptos por estos trabajos nos muestran un complejo y heterogéneo panorama. Como sostiene De Jong (2018), para abordar el proceso tanto el concepto de guerra como de genocidio nos permiten comprender los distintos contextos y la profundidad del cambio. Aquel que marca el tránsito de una situación de guerra no enunciada -guerra de fronteras- a una situación de resistencia armada frente a un genocidio. En otras palabras, el análisis en el marco de un estudio de partes combatientes que eligen sus estrategias más convenientes presenta un punto en el cual ya no podemos presuponer una semejanza en las condiciones en las cuales éstas definen sus agencias. ${ }^{25}$

En esta dirección nos preguntamos si la continuidad de algunos elementos como la existencia de cuerpos de "indios amigos" en las filas del ejército, por ejemplo, representa una continuidad de la lógica política y de la guerra, del momento previo a las campañas de 1878 en adelante.

Una fuente interesante para aproximarnos a la discusión es el testimonio de Katrülaf, brindado al antropólogo alemán Roberto Lehmann Nitsche entre 1901 y 1903, sobre la historia de su vida. Katrülaf recorre distintos episodios de su infancia y juventud desde un registro de historicidad y espacialidad muy particular que se desarma y ve impactado cuando se produce lo que él llama la "novedad". Esa novedad son las campañas militares que no solo penetran en el territorio sino que intervienen en los modos de relación social. Es decir, se modifican con esta novedad las relaciones entre winkas y che, galenses y che, entre los diferentes lonko, y entre los che y el espacio, como también las formas de transitar en él. También con la novedad Katrülaf cambia su forma de ordenar el relato, el que se vuelve lineal en lo cronológico y en lo espacial. Coincide este desplazamiento de su situación de ser libre a prisionero, engrillado, deportado, confinado y, finalmente, obligado a servir en el ejército una vez trasladado a Buenos Aires.

Katrülaf será forzado a ser soldado durante seis años luego de su arribo al cuartel de Retiro, este también fue el caso de Juan Villegas en el regimiento $2^{\underline{0}}$ de Caballería. En su cédula de enrolamiento se dice que es hijo de Chuimienllan y Calfucao, natural de Buenos Aires de veinticuatro años de edad y que entró al servicio de las armas en el expresado regimiento "como destinado sin termino por el Exmo Gobierno Nacional por ser indio prisionero en fecha 7 de julio de $1880 "{ }^{26}$ Estos casos se repiten sistemáticamente en otros cuerpos a mediados de $1885 .^{27}$ Katrülaf, en efecto, recordaba dieciocho años después de su traslado:

Cuando nos trajeron, nosotros llegamos de mañana a Buenos Aires. Entonces a todos los puros hombres jóvenes nos llevaron al cuartel. Nos sacaron esa vez. A ambos, Foyel e Inakayal, les sacaron esos jóvenes hombres, directamente esos les quitaron. Así estuvimos nosotros esa vez que nos llevaron al cuartel. Todos estuvimos seis años como soldados. Directamente así hicimos la gente. Entonces a todos nosotros se nos dejó acá como soldados esa vez. Así fuimos traídos entonces. Hace dieciocho años. ${ }^{28}$

En estos casos -en lo formal "indígenas" con uniforme- los repertorios guerreros -se los considere híbridos o no- quedan subordinados en el conjunto 
de dispositivos sociales, económicos y culturales a través de los cuales se los posicionó en condiciones asimétricas frente a las fuerzas estatales. No solo a los "jóvenes hombres" frente al ejército de línea sino a toda la población deportada frente a los mecanismos estatales y de la sociedad civil que operaron de diferentes formas hacia la desintegración de las unidades sociopolíticas y socioculturales indígenas. Por ejemplo, la fragmentación familiar y el borramiento de identidad, a través de la distribución sistemática de menores que se realizaba hacia la década de 1880 en Carmen de Patagones entre las familias de la localidad. ${ }^{29}$

Los autores que plantean el enfoque desde la guerra no postulan, por cierto, una igualdad de condiciones, sino que la piensan desde la asimetría. Nuevas propuestas en relación con este tipo de enfrentamiento abordan distintos contextos. Alejandro Rabinovich (2015), por ejemplo, plantea la opción táctica de quien se sabe inferior de no presentar batalla. Entiende esto como una elección por una guerra asimétrica. Por ejemplo, al referirse al caso del Cacique Pooti en su relación con las fuerzas del Fuerte de Carmen de Patagones hacia la década de $1820 .{ }^{30}$ Este caso nos sirve para aclarar nuestra pregunta; es decir, ¿existe en la década de1880 la misma posibilidad de elección como la que tuvo dicho cacique en el contexto de la década de1820?

Otra pregunta de fondo es en relación a la tendencia a ver sólo una posible agencia en la guerra. Esto implica en realidad dos opciones: la resistencia o la traición. En efecto, aun eludiendo el uso de estas palabras queda implícito que quien no resiste, de una forma $u$ otra, traiciona, se rinde o se cambia de bando. Incluso para el análisis de casos de las campañas de 1878-1885 se han descripto algunas presentaciones de lonko como estrategias de enfrentamiento frente a otras parcialidades para efectivizar venganzas (Escolar y Vezub, 2013). El argumento utilizado para sostener estos casos ha sido precisamente el de un "ethos guerrero" ${ }^{31}$ que caracterizaría, por ejemplo, a las parcialidades pehuenches enfrascadas en un ciclo interminable de venganzas: ${ }^{32}$ "una cadena de venganzas que se remonta al siglo XVIII y el desarrollo de la política indígeno-criolla en la frontera sur de Mendoza" (2013: 3) y que explicaría la presentación de Millaman ante las tropas argentinas en 1882: "en el caso de Millaman, estas prácticas podrían inscribirse en el ciclo de venganzas y ruptura de alianzas que definieron su colaboración con los comandos argentinos " (2013: 38). Los autores presentan una explicación para la clausura de dichos ciclos:

$[\ldots]$ hay que resaltar que a la vez que los agentes estatales se apoyaron en los enfrentamientos de generaciones para imponerse sobre las sociedades locales, fue el mismo Estado (nacional, provincial) quien clausuró el ciclo de venganzas al monopolizar la violencia (Escolar y Vezub, 2013: 32).

La propuesta de un único ciclo de guerra -en el cual se desarrollan venganzas "infinitas" aprovechadas por los agentes estatales para que el Estado impusiese el monopolio de la violencia- está en relación con un concepto de guerra que parece abarcarlo todo -guerra social total- y que, al mismo tiempo, los autores refieren como parte de un proceso de popularización o hibridación.

Al mismo tiempo el foco en la agencia solo en términos guerreros es restrictivo. Volviendo a la propuesta de Sourruille para el caso Nahuelpán cuando identifica como la derrota histórica del mismo a su desalojo en 1937 (2017: 96), cabe la pregunta de por qué el desalojo de Nahuelpán -la "derrota"-, sería el momento de la pérdida de su "entidad política". Quizás el concepto de subalternidad en el análisis permita no reducir la visibilidad de la agencia solo a la
29. Ver por ejemplo los registros de bautismos y de vecindad de Carmen de Patagones, Archivo Emma Nozzi.

30. Citado en Ratto (1998: 31)

31. "Cierto ethos guerrero parecía ganarlos a todos, indígenas y criollos incluidos los expedicionarios de 1880 y la subcultura de la que participaban" (Escolar y Vezub, 2013: 44).

32. Literalmente los autores hablan de "la venganza infinita en las guerras del sur de Mendoza y Neuquén" (Escolar y Vezub, 2013: s/n). 
33. Ver, entre otros, el caso de Juan Nancucheo en los primeros años de la década de 1880 , o la utilización del término pehuenche para reconstruir la presencia de indios maloneros en el contexto de las campañas del año 1883 (Delrio, 2005: 34-84). de aquellos "caciques" reconocidos por el estado y entender las redefiniciones de la política mapuche, los modos de construcción de prestigio y los procesos de comunalización en contextos post-genocidas. El concepto de genocidio identifica al despliegue de violencia abierta, incluyendo los enfrentamientos bélicos, como un fin y un medio. Como un fin, el de eliminar a lo que se ha identificado como otro orden político, económico y social objeto de las políticas genocidas, al cual se ha estigmatizado y aun se le niega el constituir un orden social. Más allá de los siglos de relaciones fronterizas criollo-indígenas esta producción discursiva es también performativa de este tipo de diferencia dicotómica. Caciques amigos devinieron, en breve, en la principal amenaza a la civilización ${ }^{33}$ mientras que los presentados y nuevos reclutados dejarán de ser considerados miembros de "tribus". En tanto medio, se propone la conformación de una sociedad nacional europeizada que no contempla la supervivencia de un orden social y cultural indígena. La implementación de dicha violencia sobre los cuerpos y sobre los colectivos ha sido muy variada y heterogénea.

Los trabajos que han utilizado el término genocidio han estado en su mayor parte relacionados con el seguimiento de estos casos particulares y el abordaje de sus estrategias dentro de las nuevas relaciones sociales en las cuales dicha población fue subalternizada.

A partir de la utilización de un corpus conformado por la memoria social, la documentación de distintos tipos de archivos y fuentes secundarias se ha enfocado en casos individuales, familiares y grupales y sus trayectorias tanto en el contexto del sometimiento como en las décadas subsiguientes. Casos como los del lonko Pincén, pero también de María Roca o las familias Araujo, Cheuquelén, Peñalba o Mansilla entre otras que a lo largo del siglo XX forman parte de las comunidades que rastrea Nagy (2013) en la provincia de Buenos Aires; los procesos de comunalización y (des)territorialización en Pulmari, Neuquén, de las familias Catalán, Sandoval, Puel, Salazar, Aigo, Quidulef, Nanco, Reyes, Catrileo, Añiñir, Gil y Antilef desde la conquista hasta la actualidad que aborda Papazian (2007); el derrotero de Nahuelquir y el proceso de conformación de la Colonia Cuchamen, Chubut, a partir de estrategias de negociación de las familias Napal, Necul, Huenchunao, Meli, entre muchas otras en el contexto del sometimiento desde 1872 hasta 1943 (Delrio, 2005); la descripción de estrategias y destinos de la llamada "chusma", sin referenciamiento a caciques reconocidos por el estado, tanto en el momento de las campañas como con posterioridad en la disputa por recursos y en los sistemas de explotación que realiza Pérez (2016) o la descripción de los traslados forzados de ranqueles a los ingenios azucareros de Tucumán y Misiones y la agencia de los mismos en el contexto de concentración que realizan Sosa y Lenton (2018) describiendo la prisión, concentración, deportación y huida de Yancamil y tantos otros. Al mismo tiempo también fueron abordados en el análisis los marcos interpretativos de la memoria social y las narrativas sobre el awkan o winkamalon (Malvestitti y Delrio, 2018); los diferentes regímenes de historicidad y de valor involucrados en estos procesos (Delrio, 2014); y las nuevas estrategias de comercialización (Cañuqueo et al., 2007). En efecto, comprender dentro de la periodización la implementación de un genocidio se relaciona dialógicamente con el trabajo de descripción de las formas de reorganización política, social, económica e ideológica luego del embate bélico. Esto ha llevado a profundizar y diversificar el análisis de la agencia más allá de la resistencia armada o como venganza sino en términos de un saber hacer, o aprender a cómo vivir en el estado, a través del enfoque en los procesos de formación de nuevas comunidades, las estrategias para el acceso a la tierra, las formas de 
organización políticas, los sistemas de intercambio, las formas de producción, el parentesco y la relacionalidad desplegados desde fines del siglo XIX, y que permiten comprender los procesos actuales en marcha.

\section{Guerra y genocidio}

\begin{abstract}
Probablemente, la ausencia de grandes batallas conjugada con la abundancia de bajas -la memoria de Guerra y Marina de 1878 consigna más de 10.000 personas entre muertos, heridos y prisioneros de toda edad y géneroexpliquen la condición social de la guerra. No hubo grandes conflagraciones pero sí grandes movilizaciones, operaciones de control demográfico y territorial, desplazamientos sobre el terreno y restructuración violenta de la población (Escolar et al., 2015).
\end{abstract}

Escolar, Vezub y Salomón Tarquini encuentran una explicación en el concepto de guerra social (total) para responder una pregunta que todos los historiadores se han realizado, de una forma $\mathrm{u}$ otra, en relación con la particularidad de las llamadas "campañas al desierto": ¿por qué la guerra no parece una guerra, al menos no una convencional?

Nicolas Richard llama como "guerras de conquista o guerras coloniales de la América republicana" a la ocupación o anexión militar de los territorios indígenas libres desde mediados del siglo XIX. Los define como distintos frentes que integran una misma secuencia histórica en la cual se movilizó un mismo estrato técnico militar -tren, telégrafo, arma a repetición-, se compartió un mismo marco ideológico y se pusieron en circulación los mismos actores internacionales -misioneros, militares, ingenieros. Afirma que estos eventos conectan entre sí y con otros tantos teatros coloniales -las campañas coloniales al África, la reducción de maoríes en Nueva Zelanda o la conquista del oeste americano. Lo define como el "momento colonial" de las repúblicas sudamericanas y llama la atención sobre el hecho de que para la historiografía convencional "toda esta gente y todos estos territorios fueron conquistados sin que hubiera guerra". Refiere así a las distintas formas con las que se denominaron estos eventos, por ejemplo "se tomó posesión" de una isla, "se conquistó un desierto". El autor ejemplifica con el caso de Francia, donde se reserva el término guerra para los enfrentamientos con otros estados y se omitió hablar de guerra en las conquistas coloniales (Richard, 2015: 2-3).

No obstante, en la comparación de casos observamos que en el caso argentino si bien se utiliza el término "conquista del desierto", la definición del sintagma ha estado siempre relacionada con una epopeya militar. En efecto, ha articulado las ideas que legitiman y despolitizan el avance estatal sobre pueblos soberanos -reconocidos otrora por la misma documentación estatal- pero vinculan claramente la figura de un héroe y conductor militar, la consolidación de una estructura militar nacional y establecen una memoria guerrera a ser preservada por generaciones. Esto claramente fue retomado, como fuera señalado arriba, en el contexto de la última dictadura en Argentina, cuando se construyó una narrativa épica de la conquista, que -parafraseando a Balibar (1990: 283)- resaltó los "símbolos y fetiches del carácter nacional". Esta narrativa nacionalista construyó como "tiempo épico" sucesos que le eran contemporáneos. El mismo Roca afirmaba que era una pena que "estas románticas campañas llegasen a su fin" ${ }^{34}$ El esfuerzo fue dirigido a imprimir en el formato de la crónica militar, en los mismos partes y arengas a la tropa, un estilo épico. Los enfoques historicistas de literatos argentinos como Leopoldo
34. Carta de J. Roca a C. Villegas, Buenos Aires (28/4/1883), reproducida en Walther (1980: 547-548). 
35. Utilizando el género biográfico, Lugones comparaba a Roca con los conquistadores romanos (1938: 22), mientras que Gálvez ([1946] 1967), citando un extenso corpus documental y bibliográfico, elaboró un elogio de la vida de Ceferino Namuncura hijo del último gran cacique enemigo del estado argentino y luego devenido en coronel de su ejército nacional.
36. Es a partir de Williams (1988) que se desarrolló el concepto. Los autores no hacen relación con otras definiciones de guerra civil, social, guerra total o absoluta.
Lugones (1938) y Manuel Gálvez (1946) contribuyeron, también, a la difusión de esta interpretación histórica en clave universal. ${ }^{35}$

Richard sostiene que se trata del "momento fundante en la relación entre estas sociedades y los estados nacionales" (2015: 3) y define como guerras coloniales a la "multiplicidad de formas de la guerra que pueblan el archivo sudamericano". Dentro de esta, por ejemplo, incluye al cuatrerismo como guerra. Sostiene que la misma: "puede también tomar la forma de una situación mucho más confusa y casi estadística, un conjunto de "incidentes aislados" y muertes individuales, una "intensidad" excepcional en el mapa criminal común, como la tasa excepcionalmente alta de indígenas muertos por bala" (2015: 5). Concluye en que si Sudamérica:

es la región del mundo en la que más gente muere por bala sin estar en guerra: ¿No habrá un problema con la definición de guerra? Cotidianamente mueren en el Chaco o en el Mato Grosso indígenas baleados por colonos y estancieros -forma subrepticia, mañosa y paraestatal de la guerra que acompaña históricamente el avance del frente de colonización. Pero por otro lado, va apareciendo también una multiplicidad de formas anteriores, locales, de hacer la guerra, una diversidad de culturas y prácticas guerreras resilientes que se articulan, se sobrescriben y se infiltran mutuamente (Richard, 2015:5).

¿Qué posibilidades abre identificar los episodios de violencia señalados -cuatrerismo, represión policial y parapolicial, pero también desalojos, amedrentamiento y discriminación-, como guerra asimétrica o interpretarlos dentro de los procesos de construcción de una estructura social profunda? En otras palabras, ¿cuál es el concepto más abarcativo por detrás de las definiciones de guerra y genocidio?

En este punto la propuesta de Escolar, Vezub y Salomon Tarquini (2015) identifica al proceso en las Pampas y la Patagonia como una guerra social total, a la cual definen desde el concepto de proceso social total de Raymond Williams (1988). ${ }^{36}$ Para Williams la cultura es el "proceso social total" en el cual las personas definen y configuran sus vidas. El autor propone que el concepto de hegemonía está por encima ya que relaciona al "proceso social total" con las distribuciones específicas del poder, subordinación y dominación que hay en las relaciones sociales. A diferencia de Williams los autores afirman que el concepto de guerra -que reemplaza a la cultura como proceso social total- es superador en el análisis al concepto de hegemonía, quedando en el lugar central para identificar procesos y relaciones -las redes previas a la conquista, la interpenetración de los grupos sociales y la heterogenidad que caracterizaba a la formación estatal y a las sociedades criollo-indígenas. En breve, se propone la interpenetración de los grupos sociales intervinientes en una guerra social total en la cual no habría víctimas ni victimarios sino agencias, elecciones de estrategias en un enfrentamiento de larguísima data caracterizado por el mestizaje y la hibridez de los llamados procesos de popularización.

Por su parte, la utilización del concepto genocidio, en tanto medio en la construcción de un orden social, ha llevado a plantear un proceso hegemónico. El cual, en el tiempo, se expresa más allá de los eventos de violencia, como relaciones sociales que incluyen también aquellas entre memorias, eventos, archivos y representaciones. En esta dirección han sido utilizadas definiciones conceptuales de diferentes autores, quienes en el análisis de los modos de producción, de sociedad y de estado, construidos a partir de la violencia fundante, los han denominado como cultura del temor (Taussig, 2006), violencia 
estructural (Moses, 2008) y zona gris (Levi, 2006). Estas definiciones habilitan a describir los lugares, formas y performances que articulan y hacen un sistema de relaciones sociales particular.

Para el caso que aquí nos convoca, y parafraseando a Moses (2008), me refiero a la "sociedad de colonos" que se conforma luego del genocidio en el norte de la Patagonia; esta ha sido sostenida a través de la elaboración cultural del miedo. Como señala Taussig (2006: 41) la experiencia del terror es significativa para la manipulación de una sociedad siendo que no es unilineal e involucra tanto a dominadores como dominados. Pero es claro, sostiene, "que el victimizador necesita de la víctima para el propósito de construir verdad, objetivando las fantasías del victimizador en el discurso del otro" (2006: 40). Esta construcción cultural incluye la reificación del mal en los mismos cuerpos -el autor lo ejemplifica con los casos del negro, judío, indio y la mujer. No solo como un problema artístico sino político ya que es un discurso que tiene potencialidad alucinatoria, podríamos agregar, para establecer relaciones entre eventos, archivos, memorias y narraciones con consecuencias sobre los cuerpos de las personas, transformándose el uso del terror de ser un medio a ser el fin en sí mismo. Así, para Taussig, las narrativas -como aquellas existentes en la memoria social oral- son en sí mismas evidencias del proceso por el cual una cultura del terror fue creada y sostenida (2006: 45).

En efecto, en el norte de la Patagonia la violencia y la represión estatal fueron acompañadas de olvido, de victimización y de temor. En la estructura profunda de la sociedad de colonos se produce la imposición y usurpación de tierras, fundada en los superiores derechos de unos (colonos) sobre otros (indígenas). La propuesta de este autor procura comprender la relación entre estructura y agencia, analizando cómo se encarna en la conciencia de los colonos la idea de seguridad, amenazada por la "inevitable resistencia indígena" (Moses, 2008: 263). Este autor sostiene que el genocidio es tanto un acto de odio racial como de seguridad y, por lo tanto, no sólo un crimen de estado sino de individuos (Moses, 2008: 264). ${ }^{37}$

Se trata, al mismo tiempo, de una zona gris, de temor, de excepcionalidad donde, como señala Levi (2006), los límites entre unos y otros son borrados, aumentando así la eficacia del estado -acá se refiere al campo de concentración(Levi, 2006: 83). Además sostiene que el mismo lager no tuvo una estructura simple y que no podía ser reducido a dos grupos -víctimas y victimarios- ya que el nosotros perdía su límite, el enemigo estaba "entre nosotros" a través de la figura de los prisioneros privilegiados.

Cómo señala Taussig, es a través de un rumor, de las contadas, "donde la ideología y las ideas devienen emocionalmente poderosas y entran en una circulación social activa" (2006: 50). Así, por ejemplo, años después de finalizadas las campañas, Clemente Onelli publicaba algunas de las contadas que circulaban en los fogones en la Patagonia en un periódico porteño. Mencionaba los casos de prácticas de tiro sobre prisioneros arrojados al agua, el caso del fusilamiento del cacique Millatur, y el de un soldado famoso por degollar indígenas, entre otros, y señalaba: "Historias esas, no conocidas, [...] forman todavía tema de conversación en los fogones de los ranchos neuquinos" ${ }^{38}$

En la nueva sociedad de colonos muchos fiscaleros serán arrojados, desalojados, encarcelados y trasladados -con balas o no- y aún más asesinados al ser identificados una y otra vez como la amenaza a los bienes y al orden social. Violencia que responde ya no a una estrategia asimétrica planteada desde
37. Para Moses el genocidio es también resultado de las acciones de los mismos colonos. Dicha estructura deviene encarnada en la conciencia de los colonos cuando la seguridad aparece amenazada por la "inevitable resistencia indígena" (2008: 263).

38. Archivo General de la Nación, Sala VII, Fondo Onelli, Tomo II, p. 51. 
39. El tema es tratado por Samir Benavides (2006: 140).

40. Mass atrocity response operations (MARO). A military planning handbook; Responsability to protect $\left(\mathrm{R}_{2} \mathrm{P}\right)$.
41. La estigmatización y la violencia hacia los pueblos originarios nunca desapareció por cierto, aquí me refiero al notorio cambio de discurso gubernamental y su política de seguridad, enmarcados por la gestión de Patricia Bullrich en el ministerio de seguridad. quien se siente en inferioridad bélica sino a las formas de comunalización, acceso y ocupación de la tierra de los fiscaleros mapuche-tehuelche.

En breve, las redefiniciones de la guerra -asimétrica, irrestricta, irregular o hibrida-han surgido a la luz de procesos en los cuales la figura del partisano deviene en la del terrorista, aquel eliminable en aras de la defensa de la norma. Aquel estado de excepción permanente ${ }^{39}$ en el cual no hay enemigos sino criminales y que en defensa de la seguridad se recurre a una cultura del terror, en la cual el solo uso de términos como terrorista, subversivo o mapuche pone en marcha cadenas de sentido.

Por otra parte, también el concepto de genocidio ha sido utilizado con los fines de legitimar acciones de intervención. Para el caso me remito a los protocolos MARO y R2P ${ }^{40}$ que el presidente de Estados Unidos, Barak Obama, procuró aplicar para legitimar la intervención militar en países en los cuales se identificaban prácticas genocidas.

En todo caso, la elección de los conceptos nunca deja de estar por fuera de las disputas políticas. No existen conceptos asépticos cuya elección no nos comprometa políticamente. Puntualmente y frente al caso aquí presentado considero que el concepto de genocidio, por su historia, sus usos y dimensión analítica, denuncia las asimetrías como posiciones de poder y advierte sobre las formas en que la violencia simbólica, la construcción de la otredad, devienen en prácticas de eliminación sustentadas desde estructuras de relación estatales. Por su parte el concepto de guerra asimétrica, desde su origen, ha estado al servicio de la identificación del otro ya no solo como enemigo sino como criminal, que incluso en inferioridad deviene en amenaza a la propia existencia. Más aún ha sido utilizado para englobar la agencia subalterna -más allá del enfrentamiento armado- como actos de terrorismo, tal el caso de las demandas territoriales de las comunidades mapuche-tehuelche en la actualidad.

En este sentido el concepto genocidio es una construcción contemporánea a los eventos de referencia de este artículo, representa una respuesta, un análisis, poner en palabras una denuncia y una forma de conciencia histórica sobre los procesos de conformación estatal. Este proceso, la elección y aplicación del mismo como categoría de análisis, son claramente políticos. Como también lo es la decisión de su no aplicación.

En un interesante debate, Escolar (2011) advierte que calificar al sometimiento indígena en Argentina como genocidio constituyente del estado (Lenton, 2011) podría re-instituir a los indígenas como homo sacer (sacrificable/eliminable). Por el contrario, los episodios de los últimos tres años ${ }^{41}$ que han involucrado las políticas de seguridad de la administración del presidente Macri, identificando como enemigo interno a supuestas organizaciones terroristas mapuche en Patagonia, forman parte de la construcción del discurso hegemónico del capitalismo neoliberal que clasifica como criminal no solo al antagonista político sino también la misma diferencia cultural. En febrero de 2017, en una portada del diario Clarín se anunciaba que un joven lonko había declarado la guerra al estado argentino. Lamentablemente el fantasma de la guerra había sido nuevamente agitado en Argentina y serviría, meses más tarde, para justificar muertes por la espalda de personas indefensas. 


\section{Conclusiones}

En relación con la primera pregunta del debate aquí planteado podemos afirmar que el abordaje del modo en que se construye la excepción es también una forma de comprender la norma y el poder soberano que se construye en el mismo proceso. Por lo tanto, el análisis sobre el genocidio es un abordaje que no esencializa sino que propone ver al estado como relación, en contexto y proceso.

El análisis del caso, con su complejidad y periodización, ha conducido a los/as autores/as a utilizar distintos términos y conceptos y aún más a definir otros propios. El desarrollo de las investigaciones sobre el período previo al avance estatal de 1878-1885 sobre el territorio ha permitido visualizar la complejidad de las relaciones entre sociedades criollas e indígenas identificándose una política en las fronteras caracterizada por la diplomacia, el intercambio y las estrategias de enfrentamiento y negociación. Contradiciendo así al paradigma de la guerra entre la civilización y la barbarie propuesta por los discursos hegemónicos hasta la década de 1980. El malón, el weichan y las expediciones punitivas militares, entraron al análisis mismo del avance de la frontera, la diplomacia y las estrategias políticas criollas y de los pueblos originarios. Este abordaje ha permitido incorporar cuestiones como la construcción de los llamados indios amigos y las complejas redes de relación. El debate entonces se posicionó sobre los modos en que se produjo la transición hacia la imposición de una lógica estatal. El concepto de genocidio habilita a enfocar los eventos del fin de la llamada "frontera con el indio" como parte del proceso de construcción estatal. A través del caso se hace visible en el enfoque microhistórico el modo en que se construyó el poder soberano y la excepción. Al mismo tiempo, permite relacionar el contexto de violencia con la nueva sociedad que se construye no sólo en Pampa y Patagonia, a través por ejemplo de la distribución de recursos y acceso a la tierra sino también de los imaginarios de comunidad nacional. El modo de acceso a estos procesos ha sido a través del análisis y seguimiento de casos individuales, familiares, grupales, localizados en comarcas, territorios nacionales y provincias. En gran medida, motivados por las preguntas que desde el presente se hacen al pasado, que conectan memorias, narrativas y archivos.

Los procesos enfocados coinciden entonces con la descripción de otros casos, aquellos que configuraron el contexto de creación del concepto de genocidio.

La aplicación del mismo a partir de mediados de la década de 1980 está relacionada con la historia política de nuestro país, fundamentalmente por la hegemonía del discurso de civilización y barbarie y la militarización de la llamada epopeya del desierto.

En los últimos años se nos presenta un debate que tampoco es ajeno a su contexto, especialmente en un momento de disputa sobre derechos adquiridos por los pueblos originarios desde el retorno de la democracia. Existe un cuestionamiento al derecho al acceso a las tierras suficientes para los mismos, establecido por la constitución de 1994.

Comprender el proceso de sometimiento desde un enfoque más amplio pero también específico como el concepto de genocidio abre la vía de la reparación. Este es un punto central en nuestro contexto. Al mismo tiempo que el discurso de la seguridad gana terreno en el espacio público, las nuevas formas de la guerra hacia los enemigos sociales, de la propiedad y del orden cobra la fuerza 
también a través del voto. En la actualidad las políticas de seguridad construyen como principal amenaza para la ciudadanía, no a la extranjerización de los recursos no renovables, la fuga de capitales o la imposición externa de condiciones ala política económica de país, sino a migrantes, pobres y pueblos originarios a quienes se les atribuye incluso el poder de declarar una guerra al estado. Más que detenernos sobre cómo esto es construido, la pregunta a la que intentamos contribuir es cómo y porqué esto puede ser aceptado por parte de dicha ciudadanía.

Finalmente, la dimensión jurídica implícita desde el origen del concepto de genocidio conlleva a la pregunta sobre quiénes han sido los perpetradores y quiénes las víctimas. Esta dimensión es interpretada como política o jurídicopolítica y extraña al relato historiográfico. Nos preguntamos entonces cuáles son las implicancias de incorporar o negar la dimensión jurídica y social que ha tenido en el tiempo histórico abordado -y de entonces a nuestro presentelas ideas de delito, crimen, daño, pérdida, justicia y reparación, entre otras. Entendemos que escindirlas del relato historiográfico conduce a un tipo de negacionismo que parece inhibir a la historiografía para hablar de víctimas y perpetradores, aun cuando podemos describir en múltiples detalles la comisión de un delito de lesa humanidad.

Martin Shaw (2014) propone que sin subordinar los estudios de genocidio a los de guerra estos deberían compartir un marco en común, pero considera que los estudios de guerra deberían reconfigurarse radicalmente, reconociendo al genocidio como una tendencia más grande de la guerra moderna.

Considero, quizás en una dirección similar, que la utilización de un concepto no anula al otro al punto que en una guerra pueden desencadenarse -o nogenocidios, que los conceptos continúan siendo herramientas de trabajo y pueden y deben ser redefinidos; porque, constantemente, son parte de nuestras propias agencias políticas. 


\section{Bibliografía}

》Agamben, G. (2010). Homo Sacer. El poder soberano y la vida nuda. Madrid, Pre-textos.

»Anzaldi, P. (2011). Aron, lector de Clausewitz. Revista de Instituciones, Ideas y Mercados 55: 39-70.

"Bartrop, P. (2002). The relationship between war and genocide in the twentieth century: A consideration. Journal of Genocide Research 4 (4): 519-532.

» Bassford, C. (1994). Clausewitz in English: The Reception ofClausewitz in Britain and America. New York, Oxford University Press. Disponible en Internet: http://www.clausewitz.com/ readings/Bassford/Cworks/Works.htm\#_edn5o Consultado el: 8 de abril de 2018.

» Bendersky, J. (1983). Carl Schmitt. Theorist for the Reich. Princeton, Princeton UniversityPress.

» Briones, C. y M. Carrasco (2000). Pacta Sunt Servanda. Capitulaciones, convenios y tratados con indígenas en Pampa y Patagonia (Argentina, 1742-1880). Buenos Aires, International Working Group on Indigenous Affairs, Serie Documentos en Español 29. Vinci Guerra Testimonios.

» Cañuqueo, L.; Kropff, L. yP. Pérez (2007). “El ‘paraje’ y la 'comunidad’ en la construcción de pertenencias colectivas mapuche en la provincia de Río Negro”. Actas delVIII Congreso Argentino de Antropología Social: 210-224 Salta, Facultad de Humanidades de la Universidad Nacional de Salta.

»Clausewitz, C. ([1832]1968). De la Guerra. Buenos Aires, Círculo Militar.

»De Jong, I. (2018). Guerra, genocidio y resistencia: apuntes para discutir el fin de las fronteras en pampa y norpatagonia, siglo XIX. Goiânia 16 (2): 229-254.

» De Jong, I. y S. Ratto (2008). La construcción de redes políticas indígenas en el área arauco-pampeana: la Confederación Indígena de Calfucurá (1830-1870). Intersecciones en Antropología 9: 241-26o.

» De Jong, I. y S. Ratto (2009). La construcción de redes políticas indígenas en el área arauco-pampeana: la Confederación Indígena de Calfucurá (1830-1870). Intersecciones en Antropología 9: 241-26o.

» Delrio, W. (2005). Memorias de expropiación. Sometimiento e incorporación indígena en la Patagonia (1872-1943). Bernal, Universidad Nacional de Quilmes.

» Delrio, W. (2014). “Narraciones del genocidio” en Lanata, J. L. (comp.), Prácticas genocidas y violencia estatal en perspectivas transdiciplinar: 166-181. San Carlos de Bariloche, IIDyPCa-CONICET/UNRN.

»Delrio, W. (2015). Caciques, concentraciones y reclutamientos. Campañas de conquista e imposición estatal en el norte de la Patagonia. Revista Tefros 13 (1): 149-181.

» Delrio W. y P. Pérez (2018). “A ambos lados de la cordillera: similitudes y diferencias en la construcción de la sociedad de colonos tras la ocupación militar del Wallmapu" en Pozo Menares, G. (ed.), Expoliación y violación de los derechos humanos en territorio mapunche. Cartas del padre Sigifredo, Misión de Panguipulli, año 1905: 443-456. Santiago de Chile, Ocho Libros Editores.

» Delrio, W.: Lenton, D.; Musante, M.; Nagy, M.; Papazian, A. y P. Pérez (2010). Discussing the Indigenous Genocide in Argentina: Past, Present and Consequences of Argentinean State Policies toward Native Peoples.Genocide Studies and Prevention 5: 138-159. 
» Díaz, S.; Lenton, D.; Nagy, M.; Papazian, A.; Pérez, P. y W. Delrio (2007). “Aportes para una reflexión sobre el genocidio y sus efectos en relación a la política indígena en Argentina". ISociología, Revista electrónica de Ciencias Sociales. Disponible en Internet: http:// www.isociologia.com.ar 46-61. Consultado el: 6 de octubre de 2012.

»Escolar, D. (2011). Reflexiones de los autores y la editora sobre el debate. Corpus. Archivos virtuales de la alteridad americana1 (2). Disponible en Internet: http://ppct.caicyt.gov.ar/ index.php/corpus. Consultado el: 8 de abril de 2018.

»Escolar, D. (2013). Huarpe archives in the Argentine desert: Indigenous Claims and State Construction in Ninetheenth-Century. Hispanic American Historical Review 93 (3): 451-483.

»Escolar, D. y J. Vezub (2013). ¿Quién mató a Millaman? Venganzas y guerra de ocupación nacional del Neuquén, 1882-3. Mundo Nuevo, Nuevos Mundos. Disponible en Internet: http://nuevomundo.revues.org/65744\#entries. Consultado el: 8 de abril de 2018.

» Escolar, D.; Vezub, J. y C. Salomón Tarquini (2015). “La “Campaña del Desierto (18701890): notas para una crítica historiográfica” en Lorenz, F. (comp.), Guerras de la historia argentina: 223-247. Buenos Aires, Ariel.

»Feierstein, D. (2007). El genocidio como práctica social. Entre el nazismo y la experiencia argentina. Fondo de Cultura Económica (FCE), Buenos Aires.

» Fein, H. (1984). "Scenarios of Genocide: models of Genocide and Critical Responses”, en Charny, I. (ed.), Toward the Understanding and Prevention of Genocide: 3-31. Boulder, Westview Press.

» Fridman, S. (1979). “La situación del indígena a través del periodismo” en Congreso Nacional de Historia sobre la Conquista del Desierto, General Roca, 6-10 de noviembre tomo IV: 377-387. Buenos Aires, Academia Nacional de la Historia.

» Gálvez, M. ([1946] 1967). El santito de la toldería. La vida perfecta de Ceferino Namuncura. Biblioteca Maestros del Idioma 10. Rosario, Editorial Apis.

» González, G. (2017). De la Guerra Asimétrica a la Guerra Híbrida. Visión Conjunta. 9 (16): 20-24.

» Iñigo Carrera, N. (2017). “Notas sobre el concepto de guerra civil”. Ponencia presentada en las Terceras Jornadas Internacionales sobre conflictos y problemáticas sociales y Quintas Jornadas Interdisciplinarias sobre conflictos y problemáticas sociales en la región del Gran Chaco. Facultad de Ciencias Económicas, UNNE. Resistencia, Chaco 7 al 9 de junio.

» Laleff Ilief, R. (2012). “El estadio actual de la guerra desde una visión teórico- política”. Ponencia presentada en el Cuarto Congreso Uruguayo de Ciencia Política. Montevideo. Asociación Uruguaya de Ciencia Política, Universidad Católica de Uruguay. Montevideo, 14 al 16 de noviembre. Disponible en Internet: http://www.aucip.org.uy/docs/cuarto_ congreso/11121112\%20-\%2oLaleff\%2ollieff,\%20Ricardo.pdf. Consultado el: 2 de septiembre de 2018.

» Lemkin, R. (1944). Axis Rule in Occupied Europe. Washington.

" Lenton, D. (1994). “La imagen en el discurso oficial sobre el indígena de pampa y Patagonia y sus variaciones a lo largo del proceso histórico de relacionamiento: 18801930". Tesis de Licenciatura. Facultad de Filosofía y Letras, Universidad de Buenos Aires.

"Lenton, D. (2005). De centauros a protegidos. La construcción del sujeto de la política indigenista argentina a través de los debates parlamentarios. Tesis doctoral, Buenos Aires, Facultad de Filosofía y Letras, Universidad de Buenos Aires. Disponible en Internet: http://repositorio.filo.uba.ar/handle/filodigital/1268. Consultada el: 8 de abril de 2018

»Lenton, D. (ed.) (2011). Debate. Genocidio y política indigenista: debates sobre la potencia explicativa de una categoría polémica. [Reflexiones de los autores y la editora sobre el debate]. Corpus. Archivos virtuales de la alteridad americana 1 (2). Disponible en 
Internet: http://ppct.caicyt.gov.ar/index.php/corpus. Consultado el: 2 de marzo 2018.

"Lenton, D. y J. Sosa (2009). “La expatriación de los pampas y su incorporación forzada en la sociedad tucumana de finales del siglo XIX”. Jornadas de Estudios Indígenas y Coloniales: 89-112. S. S de Jujuy, Centro de Estudios Indígenas y Coloniales (CEIC).

» Levaggi, A. (2000). Paz en la frontera. Historia de las relaciones diplomáticas con las comunidades indígenas en la Argentina (Siglos XVI-XIX). Buenos Aires, Universidad del Museo Social.

» Levi, P. (2006). “The Grey Zone” en Scheper-Hughes, N. y P. Bourgois (eds.), Violence in War and Peace: 83-90. Singapur, Blackwell.

» Liang, Q. y W. Xiangsui (1999). Unrestricted Warfare. Beijing, PLA Literature and Arts Publishing House.

» Lind, W.; Nightengale K.; Schmitt, J. F.; Sutton, J. W. y G. Wilso (1989). Changing Face of War: Into The Fourth Generation. Marine Corps Gazette, October 73 (10):22-26.

»Llanquinao, M. C. y G. Pozo Menares (2013). Historia y conocimiento oral mapuche: sobrevivientes de la "Campaña del Desierto" y "Ocupación de la Araucanía" (1899-1926). Santiago de Chile, Consejo Nacional de la Cultura y las Artes.

» Lugones, L. (1938). Roca, Buenos Aires, Imprenta Coni.

» Malvestitti. M. y W. Delrio (2018). “Memorias del Awkan” en Delrio, W; Escolar, D.; Lenton, D. y M. Malvestitti (comps.), En el país de nomeacuerdo. Archivos y memorias del genocidio del estado argentino sobre los pueblos originarios 1870-1950: 23-68. Viedma, Editorial de la Universidad Nacional de Río Negro.

" Moses, D. (2008). Moving the Genocide Debate Beyond the History Wars. Australian Journal of Politics and History 54 (2): 248-270.

» Nagy, M. (2013). Estamos vivos. Historia de la comunidad indígena cacique Pincén, provincia de Buenos Aires. Buenos Aires, Antropofagia.

» Nagy, M. y A. Papazian (2009). “De la Isla como Campo. Prácticas de disciplinamiento indígena en la Isla Martin García hacia fines s. XIX”. Actas de las XII Jornadas Interescuelas/ Departamentos de Historia: 134-143. Bariloche, Universidad Nacional del Comahue.

» Nagy, M. y A. Papazián (2018). “De todos lados, en un solo lugar. La concentración de indígenas en la isla Martín García 1871-1886” en Delrio, W; Escolar, D.; Lenton, D. y M. Malvestitti (comps.), En el país de nomeacuerdo. Archivos y memorias del genocidio del estado argentino sobre los pueblos originarios 1870-1950: 69-98. Viedma, Editorial de la Universidad Nacional de Río Negro.

" Navarro Floria, P. (2001). "El salvaje y su tratamiento en el discurso político argentino sobre la frontera sur, 1853-1879”. Revista de Indias LXI (222): 345-376.

» Papazián, A. (2007). “Identidades creadas. Construcción ciudadana y genocidio. Racionalidad Occidental, Estado y Violencia en Turquía” ponencia presentada en las XI Jornadas Interescuelas/Departamentos de Historia. Departamento de Historia. Facultad de Filosofía y Letras. Universidad de Tucumán, San Miguel de Tucumán 19 al 22 de septiembre.

»Pérez, P. (2016). Archivos del silencio: estado, indígenas y violencia en la Patagonia central 1878-1941. Buenos Aires, Prometeo Libros.

» Pérez, P. y W. Delrio (2017). “Más allá del desierto. El genocidio como evento estructurante en la norpatagonia argentina" ponencia presentada en el IX Congreso Chileno de Antropología. Castro, Chile 6 al 9 de enero. (Simposio: Genocidio, racismo y expoliación hacia los Pueblos Originarios en el sur de Chile y Argentina: colonialismo republicano en perspectiva interdisciplinaria). 
»Rabinovich, A. (2015). De la historia militar a la historia de la guerra. Aportes y propuestas para el estudio de la guerra en los márgenes. Corpus 5 (1). Disponible en Internet: http:// corpusarchivos.revues.org/1405. Consultado el: 6 julio de 2016.

»Rancière, J. (1996). El Desacuerdo. Política y Filosofía. Buenos Aires, Ediciones Nueva Visión.

» Ratto, S. (1998). "Relaciones interétnicas en el Sur bonaerense, 1810-1830. Indígenas y criollos en la conformación del espacio fronterizo” en Villar, D.; Jiménez J. F. y S. Ratto (eds.), Relaciones interétnicas en el Sur bonaerense, 1810-1830: 20-47. Bahía Blanca, Universidad Nacional del Sur/IEHS.

» Richard, N. (2015). Presentación: La guerra en los márgenes del Estado, simetría, asimetría y enunciación histórica. Corpus, 5 (1). Disponible en Internet: http:// corpusarchivos.revues.org/1405. Consultado el: 6 julio de 2016.

»Shaw, M. (2014). Qué es el genocidio. Buenos Aires, Prometeo.

»Samir Benavides, F. (2006). Excepción, decisión y derecho en Carl Schmitt. Argumentos 19 (52): $125-145$.

»Schmitt, C. ([1932] 1963). El concepto de lo político. Texto de 1932 con prólogo y tres corolarios de Carl Schmitt. Traducido de la edición de 1963 por Dénes Martos. Katariche. Disponible en Internet: https://www.scribd.com/people/view/3502992-jorge. Consultado el: 14 de agosto de 2018.

»Sohr, R. (2009). Los peligros de la guerra asimétrica. Nueva sociedad. Octubre. Disponible en Internet: http://nuso.org/articulo/los-peligros-de-la-guerra-asimetrica/. Consultado el: 20 de agosto de 2018 .

"Sourrouille, M. (2017). Nahuelpan, Colonia 16 de octubre y Argentine Southern Land Co.: La colonización del territorio nacional del Chubut (1885-1937). Tesis doctoral. Buenos Aires, Facultad de Filosofía y Letras, Universidad de Buenos Aires. Disponible en Internet: http://repositorio.filo.uba.ar/handle/filodigital/6117. Consultado el: 12 de agosto de 2018.

"Sosa, J, y D. Lenton (2018). "De la mapu a los ingenios. Derroteros de los prisioneros indígenas de la frontera sur” en Delrio, W; Escolar, D.; Lenton, D. y M. Malvestitti (comps.), En el país de nomeacuerdo. Archivos y memorias del genocidio del estado argentino sobre los pueblos originarios 1870-1950: 137-200. Viedma, Editorial de la Universidad Nacional de Río Negro.

» Stanton, G. (1998) Eight Stages of Genocide. Disponible en Internet: http://www. genocidewatch.org/aboutgenocide/8stagesofgenocide.html.

»Consultado el: 10 de mayo de 2018.

» Tamagnini, M. y G. Pérez Zavala (2002). “El debilitamiento de los ranqueles: el tratado de paz de $1872 y$ los conflictos intraétnicos” en Nacuzzi, L. (comp.), Funcionarios, Diplomáticos y Guerreros. Miradas hacia el otro en las fronteras de pampa y Patagonia (Siglos XVIII y XIX): 119-157.Buenos Aires, Sociedad Argentina de Antropología.

» Taussig, M. (2006). “Culture of terror -Space of death.Roger Casement's Putumayo Report and the Explanation of Torture" en Scheper-Hughes, N. y P. Bourgois (eds.), Violence in War and Peace: 39-53. Singapur, Blackwell.

" Theriault, H. (2001). Universal social theory and the denial of genocide: Norman Itzkowtiz revisited. Journal of Genocide Research 3 (2): 241-256.

» Tse-tung, M. [1938] (1976). "Sobre la guerra prolongada” en Mao Tse-tung, Obras Escogidas Tomo II: 113-200. Pekin, Ediciones en lenguas extranjeras, $3^{\circ}$ impresión; primera edición 1968). Disponible en Internet: https: //www.marxists.org/espanol/mao/ escritos/PW38s.html. Consultado el: 17 de octubre de 2018. 
»Van Creveld, M. (1991). The Transformation of War. New York, The Free Press.

»Vezub, J. (2009). Valentín Saygüeque y la Gobernación Indígena de las Manzanas. Poder y etnicidad en la Patagonia Septentrional (1860-1881). Buenos Aires, Prometeo Libros.

»Vezub, J. (2013). “El proceso de popularización indígeno-criollo en Pampa y Patagonia del siglo XIX” en Fradkin, R. y G. Di Meglio (comps.), Hacer política. La participación popular en el siglo XIX rioplatense: 333-362. Buenos Aires, Prometeo.

»Villar, D. y J. F. Jiménez (2003). “Conflicto, poder y justicia. El cacique Martín Toriano en la cordillera y las pampas (1818-1832)" en Villar, D. (ed.), Conflicto, Poder y Justicia en la frontera bonaerense. 1818-1832: 131-228. Bahía Blanca y Santa Rosa, Dpto. de Humanidades, Universidad Nacional del Sur, Facultad de Ciencias Humanas, Universidad Nacional de La Pampa.

»Walther, J. C. (1980). La Conquista del Desierto. Buenos Aires, EUDEBA.

»Williams, R. (1988). Marxismo y literatura. Barcelona, Península.

»Wolfe, P. (2006). Settler Colonialism and the Elimination of the Native. Journal of Genocide Research 8 (4):387-409. 